\title{
miRNA: The nemesis of gastric cancer (Review)
}

\author{
XIAOHUI XU ${ }^{1 *}$, XIAODONG YANG $^{1 *}$, CHUNGEN XING $^{1}$, SHUYU ZHANG $^{2}$ and JIANPING CAO ${ }^{2}$ \\ ${ }^{1}$ Department of General Surgery, The Second Affiliated Hospital of Soochow University, Suzhou 215004; \\ ${ }^{2}$ School of Radiation Medicine and Protection, Medical College of Soochow University, Suzhou 215123, P.R. China
}

Received January 10, 2013; Accepted June 13, 2013

DOI: $10.3892 / 01.2013 .1428$

\begin{abstract}
RNAs (miRNAs) are a group of small non-coding RNAs that are 22 (18 to 25 ) nucleotides (nt) long and have been associated with a variety of diseases, including cancer. Increasing evidence indicates that miRNAs are essential in the development, diagnosis, treatment and prognosis of a variety of tumors. The utility of miRNAs as biomarkers for diagnosis and of target molecules for the treatment of cancers is increasingly being recognized. With the discovery of circulating miRNAs, a non-invasive approach for the diagnosis and treatment of cancer has been identified. This review summarizes the role of miRNAs in the development of different tumors, as well as a variety of other biological events. Moreover, this review focuses on analyzing the function and mechanism of gastric cancer-related miRNAs and investigates the importance of circulating miRNAs in gastric cancer, as well as their origin. Finally, this review lists a number of the problems that must be solved prior to miRNAs being used as reliable non-invasive tools for the diagnosis, treatment and prognosis of gastric cancer.
\end{abstract}

\section{Contents}

1. Introduction

2. Discovery of miRNAs

3. Biosynthesis and biological functions of miRNAs

4. miRNAs and cancer

5. miRNAs and gastric cancer

6. Serum/plasma miRNAs as biomarkers/signaling molecules for gastric cancer

7. Conclusions

Correspondence to: Professor Chungen Xing, Department of General Surgery, The Second Affiliated Hospital of Soochow University, 1055 Sanxian Road, Suzhou 215004, P.R. China

E-mail: cg_xing@yahoo.cn

Dr Shuyu Zhang, School of Radiation Medicine and Public Health, Medical College of Soochow University, No. 199 Renai Road, Suzhou 215123, P.R. China

E-mail: zhang.shuyu@hotmail.com

${ }^{*}$ Contributed equally

Key words: miRNA, gastric cancer, serum, plasma, biomarker, exosome

\section{Introduction}

The incidence of gastric cancer ranks fourth in males and fifth in females, while the mortality ranks third in males and fifth in females among all cancers worldwide (1). The incidence and mortality of gastric cancer in developing countries in males and females are much higher compared with developed countries (1). With improvements in diagnostic and therapeutic technology, the survival time of patients with early gastric cancer has been greatly extended. However, the prospects for the treatment of patients with advanced gastric cancer are not optimistic. At present, there are a number of non-surgical treatment approaches, although surgery remains the primary method for the radical treatment of gastric cancer.

microRNAs (miRNAs) are becoming increasingly recognized as important in cancers, including gastric cancer. To date, $>1,400$ miRNAs have been described in humans (2). Yu et al observed that in gastric cancer cell lines 17 miRNAs were upregulated and 146 miRNAs were downregulated compared with normal gastric mucosa (3). miRNAs specific to the tumorigenesis and development of tumors have become hot spots for cancer research. miRNAs are associated with the development of tumor biology, as well as the diagnosis, treatment and detection of prognosis of tumors. In addition, the reliability of miRNA detection in the circulatory system of tumor patients has also been demonstrated. One study showed that miRNA expression is closely associated with the tumorigenesis, progression and prognosis of gastric cancer (4), and the detection of miRNA in the circulating system may offer new biomarkers for gastric cancer (5). Consequently, detecting miRNAs in the serum/plasma may become a non-invasive pathway for providing a basis for the treatment, diagnosis and prognosis of gastric cancer.

\section{Discovery of miRNAs}

In 1993, Victor Ambros first identified miRNA in C.elegans (6). Simultaneously, Gary Ruvkun identified the gene Lin-14 as the first miRNA target (7). These two important findings demonstrated a new post-transcriptional gene regulation mechanism. Approximately seven years later, the importance of miRNAs was realized when Ruvkun and Horvitz identified another miRNA in C. elegans (8), and when interest was focused on another short-chain RNA, small interfering RNA (siRNA; involved in the process of RNA interference and related phenomena in plants and animals). In 2001, three research 
groups from different countries all identified 21-22 nucleotide (nt) non-coding small RNA molecules in C. elegans, Drosophila and the human body (9). These single-stranded small RNA molecules with spatial and temporal expression were different from the previously reported siRNA detected in the interference pathway (RNA interference; RNAi) and were subsequently named miRNA.

\section{Biosynthesis and biological function of miRNAs}

miRNAs are encoded by specific miRNA genes in the genomic DNA, which are first transcribed by RNA polymerase II into a stem-loop that is $\sim 500$ to 3,000 bp long (10). This initial transcript is known as pri-miRNA. These pri-miRNAs in the nucleus are further transformed into $\sim 60$ to 70-nt hairpin-shaped precursor miRNAs (pre-miRNAs) by the Drosha enzyme (a type of RNase III enzyme). Precision processing of the pre-miRNA is extremely important as this produces the 'seed' region of miRNA, which is the determining factor leading to gene silencing. This 'seed' region is the target area on the mRNA that is complementary to the 2-7 positions of the antisense miRNA oligonucleotide. The pre-miRNAs are exported into the cytoplasm by Exportin-5 (Exp-5) and cleaved by Dicer to generate 20-24 nt RNA duplexes, one strand of which is loaded into the Argonaute-containing RNA-induced silencing complex (RISC). miRNA-RISC complexes are able to silence target mRNAs via imperfect complementarity with sequences located in the 5'-UTR, coding sequences and, most commonly, the 3'-UTR (11). When pre-miRNA is transported to the cytoplasm by the transport protein Exp-5, the pre-miRNA hairpin in the cytoplasm is cleaved into two strands by Dicer (RNase III), with the release of two complementary 22-base nt chains. Subsequent to being processed by the enzyme Dicer, the antisense miRNA chain and mRNA target region complementary base pair together to form a complex with Argonaut proteins. Argonaut guides the miRNA chain to reach the target sequence on the mRNA and combines with RISC $(12,13)$. RISC combines with target mRNA at the 3'-UTR and the miRNA base pairs with the target mRNA, causing target mRNA cleavage and inhibition of protein expression (13-17).

miRNAs regulate gene expression at the post-transcriptional level (18-20). Furthermore, miRNAs are members of the small RNA family, which includes small nuclear RNA (snRNA) involved in mRNA splicing (21), small nucleolar RNAs (snoRNAs), which directly modify ribosomal RNA (22), and siRNAs, which are generated by long double-stranded RNA precursors. siRNAs also functionally regulate gene expression, similar to miRNAs (23). miRNAs are highly-conserved endogenous RNA molecules that occur in the genome of animals, plants, fungi and viruses (24). It is currently estimated that miRNAs account for $\sim 1 \%$ of the human genome (25) and they have been demonstrated to play crucial roles in the human body, including roles in growth (8), cell proliferation and cell apoptosis $(26,27)$.

\section{4. miRNAs and cancer}

Tumor-specific miRNAs. miRNAs have been associated with a variety of diseases, including cancer. Increasing evidence has demonstrated the importance of miRNAs in regulating biological characteristics common to various tumors, including self-growth signals, insensitivity to anti-growth signals, abnormal apoptosis, unlimited replication potential, sustained induction of angiogenesis and invasion and metastasis organization (28). Numerous researchers have identified tumor-specific miRNA signatures that accurately distinguish malignant tumors from various types of benign tissues, and have demonstrated that certain miRNAs are carcinogenic depending on the other gene mutations in the tumors (29). miRNA regulation in tumor cell lines directly affects cell proliferation and apoptosis, and similarly, a number of studies have identified a link between abnormal miRNA expression and intracellular signal transduction pathway abnormalities, as well as tumorigenesis (30-34). For example, miR-9 is activated by YC/MYCN, which induces cancer metastasis by regulating the metastasis suppressor protein E-cadherin (35), while miR-449a causes retinoblastoma (Rb)-dependent cell cycle arrest and cellular senescence in prostate cancer (36). Table I provides an overview of the expression of the same miRNAs in different tumor cells, the expression of different miRNAs in the same tumor cells and the associated target proteins and/or target genes of the miRNAs (35-48).

miRNAs constitute a new class of molecules that are able to promote the formation of cancer through interactions with oncogenes and/or tumor suppressor genes (49). However, different miRNAs have different signaling pathways and the target proteins/genes through which they affect the biological changes of cancer.

Circulating miRNAs in cancer. The aforementioned examples show that miRNAs have the potential to function as biomarkers for the diagnosis, treatment and prognosis of cancer, although miRNA expression profiling may not be used without a tumor biopsy. Therefore, the identification of non-invasive methods for the diagnosis and treatment of cancer has become a goal for cancer research. A number of studies have proposed that the characteristics of the cancer genome, genetic and epigenetic, may be detected in the serum and plasma of cancer patients (50). Therefore, the detection of plasma miRNA is a useful approach for the diagnosis, treatment and monitoring of the prognosis for cancer patients. miRNAs are involved in the development and differentiation of tumors and the lineage-dependent mechanism. Consequently, this becomes the basis for tumor development. Since miRNA detection by PCR is highly sensitive and of low complexity compared with protein detection, modifications of miRNAs are possible and synthetic high-affinity miRNA "capture" reagents are available, miRNAs may have a high value as biomarkers. In addition, circulating miRNAs in human blood and other body fluids are plentiful, have remarkable stability and may be measured in routine clinical diagnosis. Therefore, circulating miRNAs are considered to be extremely promising cancer biomarkers (51-53). At present, an increasing number of scholars are attempting to identify more specific and highly sensitive miRNAs from the plasma of various tumor patients for use as non-invasive biomarkers for the diagnosis, treatment and prognostic evaluation of tumors. Such a simple, feasible and acceptable method is likely to optimize the therapeutic effect for patients. In recent years, 


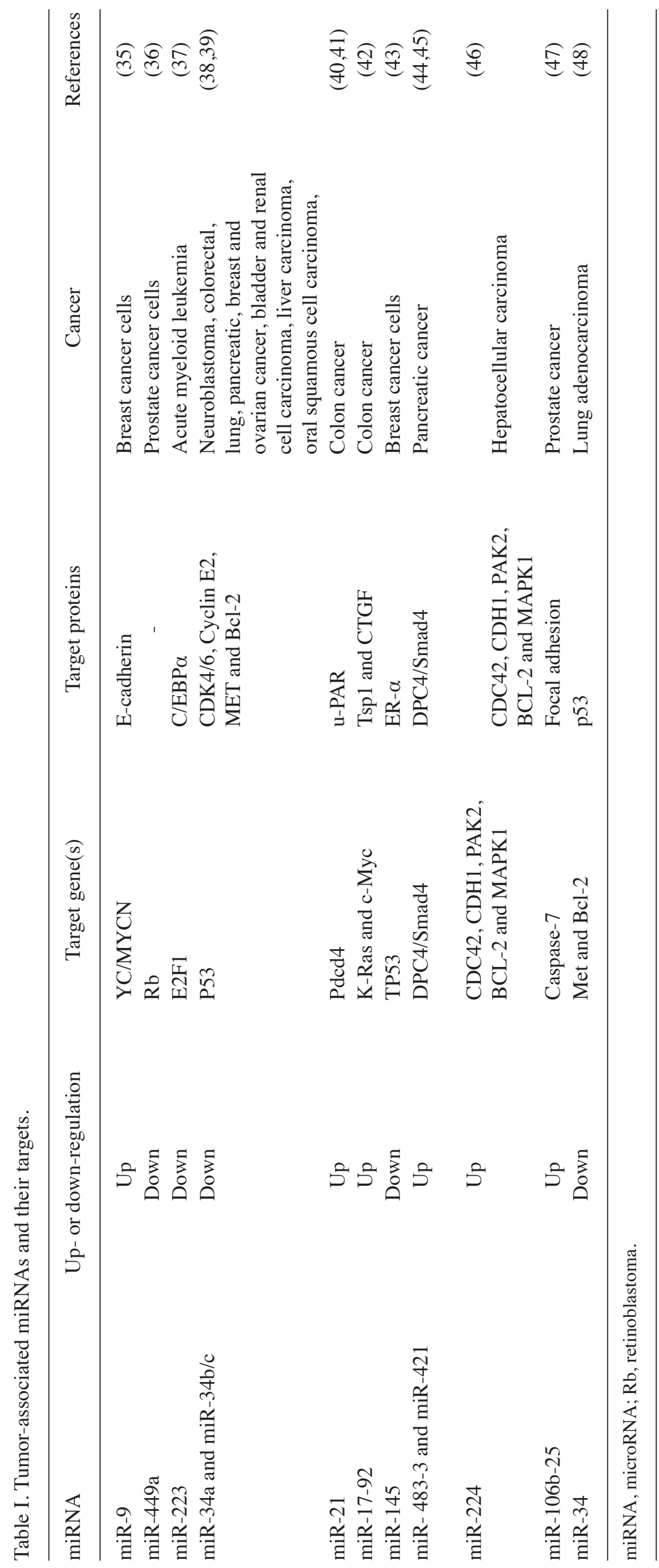


there are have been a number of studies on plasma miRNAs as biomarkers. Lawrie et al identified the first circulating miRNA in 2008 (54). The study observed that miR-21 expression was associated with the relapse-free survival of patients with diffuse large B-cell lymphoma (DLBCL) and suggested that miRNAs have potential as non-invasive diagnostic markers for DLBCL and possibly other cancers (54). Subsequently, the plasma-based detection of miRNA has become a research hot spot. Table II provides an overview of the functions of plasma or serum miRNAs in various types of cancer (55-64).

All current research results show that miRNAs have promise as novel non-invasive biomarkers for the elimination of false-positive and -negative results in routine testing. However, the source of the circulating miRNAs and how these circulating miRNAs function must be identified for the proper use of circulating miRNA biomarkers in evidence-based medicine (65).

\section{5. miRNAs and gastric cancer}

Since miRNAs have been shown to be significant factors during the progression of gastric cancer, global miRNA expression profiles have been performed using microarrays, real-time PCR or next-generation sequencing approaches. A significant number of the functions and mechanisms of miRNAs in the process of the development of gastric cancer have been identified.

Biological effects of miRNAs in gastric cancer. The incidence of gastric cancer is the result of interactions between Helicobacter pylori, genetic predisposition, eating habits and environmental factors, although oncogenes and tumor suppressor genes eventually determine gastric carcinogenesis. However, miRNAs are not only involved in oncogene-induced tumors, but also in tumors caused by tumor suppressor genes; their role in gastric carcinogenesis complements and enriches the mechanism of tumorigenesis. Table III provides an overview of the roles of various miRNAs in the proliferation of gastric cancer (66-82). Considerable progress has also been made in research into the mechanism of action of miRNAs in gastric cancer cell invasion and metastasis. Table IV provides an overview of the role of various miRNAs in the invasion and metastasis of gastric cancer (83-90).

miRNAs are pivotal in the development of gastric cancer. It is of note that certain miRNAs do not function alone and various clusters of miRNAs share functional associations. Therefore, it is extremely important to clarify whether their role is independent or synergistic with other miRNAs when the biological functions of certain clusters of miRNAs are studied.

miRNAs and gastric cancer pathology. The detection of specific miRNAs may become a potential field in marker development (91). Studies have shown that different tumors have specific miRNA expression patterns and that a variety of tumors have specific miRNA expression profiles (92). A comparative analysis of miRNA expression profiles between tumors and normal tissue suggests a new approach for the genetic diagnosis of tumors. At present, the role of miRNAs in the diagnosis and treatment of gastric cancer has increased significantly worldwide. miR-21 appears to be important in tumorigenesis due to its upregulation in almost all types of human cancer. Furthermore miR-21 is overexpressed in $92 \%(34 / 37)$ of gastric cancer samples and is thus considered to be a promising novel biomarker for gastric cancer, as well as lymph node metastasis $(93,94)$. In gastric cancer, upregulated miRNA-106a and miR-143, as well as downregulated miR-203, are associated with gastric tumor size, stage, lymph nodes and distant metastasis. Consequently, they may become a new type of potential biological diagnostic molecule for gastric cancer (95-97). A study has shown that the reduced expression of miR-574-3p occurs mainly in the early stages of gastric cancer or in cancers with a high level of differentiation, suggesting that it may be used as a marker for mild cases of gastric cancer (98).

Therefore, miRNAs are important in pathological staging, lymph node metastasis and distant metastasis of gastric cancer. If miRNA changes specific to the development of gastric cancer are identified and the stage of gastric cancer is determined, this approach may become a pathway for aiding in the diagnosis of gastric cancer by detecting this type of miRNA. However, further important information for the clinical diagnosis of gastric cancer should be provided and more clinical data must be collected to determine the feasibility.

miRNAsand gastric cancerdiagnosis and treatment. At present, the main methods of treatment for gastric cancer are surgery, chemotherapy, radiotherapy and biologically targeted therapy, of which surgery is the most important. In numerous cases, a tumor diagnostic tool also provides a therapeutic approach. There are a number of studies on gastric cancer treatment through the targeting of miRNA. For example, cell proliferation, migration and invasion in gastric cancer cells have been demonstrated to be significantly increased following miR-181b transfection, so miR-181b may be a potential molecular target for anticancer therapeutics in gastric cancer (99). Zhao et al revealed that miR-7 functions as an anti-metastatic microRNA in gastric cancer by targeting the insulin-like growth factor-1 receptor (100). Targeting the miR-7/IGF1R/Snail axis may be useful as a therapeutic approach for blocking gastric cancer metastasis. miRNAs produce a negative regulation of proteins by combining with the target mRNA, and it is possible to take advantage of their features to up- or downregulate the expression of key tumor-associated genes for therapeutic purposes. miRNAs, either as oncogenes or tumor suppressor genes, regulate the biological characteristics of gastric cancer. Inhibiting miRNAs as oncogenes or increasing miRNAs as tumor suppressor genes using antisense oligonucleotides and siRNA technology presents a new approach to biological therapy for gastric cancer. The identification of specific tumor-associated miRNA coding genes provides new targets for cancer gene therapy. Studies to identify drug targets for miRNAs, as well as small molecule compounds that are able to inhibit miRNA activity, are being conducted by predicting three-dimensional structures of the miRNA (101). Certain studies have investigated the use of anti-miRNA antisense oligonucleotides (AMOs) to reduce or knock out overexpressed tumor-associated miRNAs, producing tumor suppressor effects. The knockout of miR-21 by AMOS causes gastric cancer cell proliferation to be reduced significantly and 


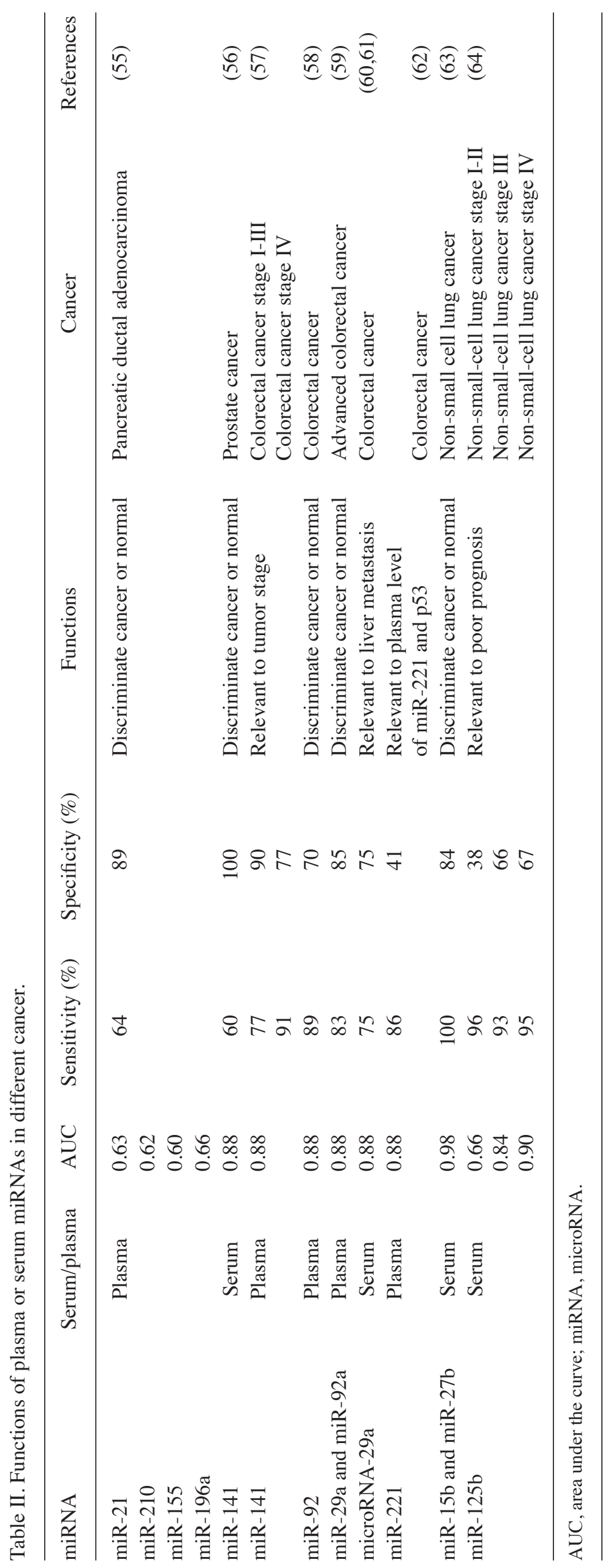




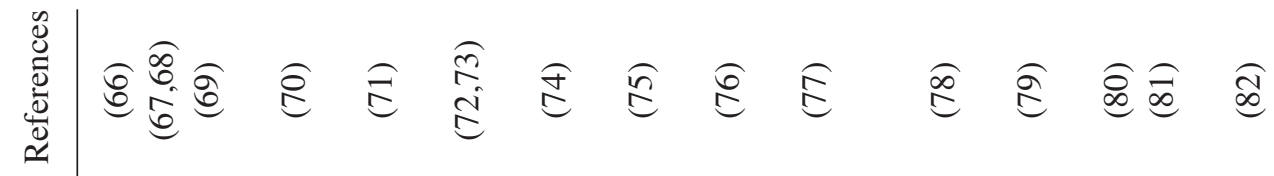

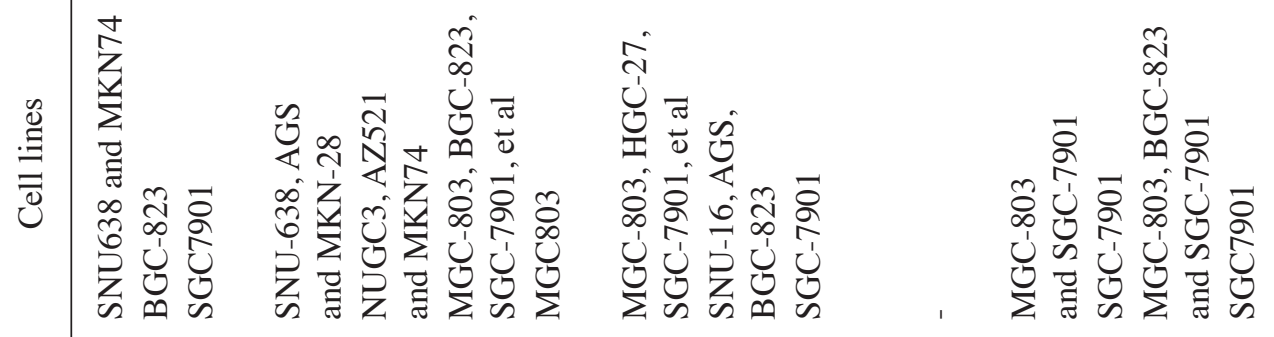
空

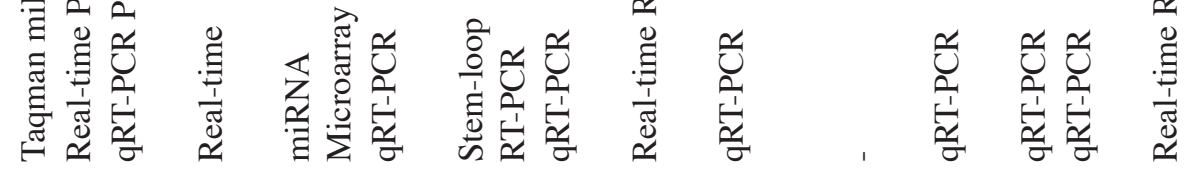

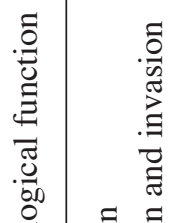<smiles>[13CH]</smiles><smiles>CCCC(C)CC</smiles>
b. कำ 
apoptosis to increase significantly (67). The downregulation of prohibitin by miR-27a may explain why the suppression of miR-27a inhibits gastric cancer cell growth, further supporting the hypothesis that miR-27a functions as an oncogene (102). The inhibition of miR-421 expression has been shown to decrease the growth of MGC-803 and SGC-7901 gastric cancer cells in vitro, upregulating the expression of its cancer-associated target genes, CBX7 and RBMXL1 (103). By contrast, the expression of tumor suppressor miRNA, induced by miRNA mimics and delivered by virus or liposome, gradually reduced the growth of gastric tumors (104). miR-34 is has been demonstrated to be involved in the downstream p53 pathway and is a potential tumor suppressor of the target genes Notch, HMGA2 and $\mathrm{Bcl}-2$, which are involved in cancer stem cell self-renewal and survival (105). The miR-34 mimics or infection with the lentivirus function as miR-34. A study has shown that miR-34 is able to impair cell growth, cause the accumulation of the cells in the $\mathrm{G}_{1}$ phase, increase caspase- 3 activation and more significantly, inhibit tumorsphere formation and growth, indicating that the restoration of the tumor-suppressor, miR-34, may provide a novel molecular therapy for p53-mutant gastric cancer (106). Resistance to chemotherapy remains one of the main obstacles for improving the overall survival and quality of life of patients with gastric cancer. Treatment with miRNA may be used as a regulatory tool for tumor cells in the chemotherapy response. Xia et al suggested that miRNAs may be involved in the development of multidrug resistance (MDR) in gastric cancer cells (107). miR-15b and miR-16 are able to modulate the sensitivity of gastric cancer cells to certain anticancer drugs, at least in part, by regulating BCL2 expression (108). So far, the potential of miRNA-based treatment for malignant disease remains largely to be developed. In addition to the previously mentioned research areas, miRNA remains to be investigated in tumor metastasis, angiogenesis and radiation resistance.

Before the application of miRNA-based therapy may occur, there are several major obstacles to overcome. First, miRNAs have multiple targets, producing the risk of accidental off-target effects, and therefore miRNA-based therapy requires careful assessment. Second, the expression of target genes is controlled by several different miRNAs, which may reduce the effect of miRNA-based therapy. Finally, there is a lack of a sufficiently specific and effective transport system for miRNA (109).

Although miRNA-targeted treatment is likely to provide a new approach for the treatment of gastric cancer, effective treatment may require a combinatorial approach to target multiple oncogenic miRNA clusters. If good use is made of multi-targeted miRNA in treatment, particularly when adaptive resistance occurs, it may produce therapeutic effects via a variety of alternative pathways in tumor cells. However, there is a long way to go before miRNAs are suitable as a therapeutic target for clinical application.

miRNAs and gastric cancer prognosis. The prognosis of patients subsequent to treatment is important for each patient and their families. In recent years, attempts have been made to identify prompt detection methods for the prognosis of gastric cancer using the fields of biochemistry, immunohistochemistry and genetic testing $(110,111)$, although a reliable, specific, 
sensitive and practical detection method has yet to be detected. However, it has been possible to identify a new method for detecting the prognosis of gastric cancer patients through the study of miRNAs. Yu et al and Chen et al detected high expression levels of miR-93 in gastric cancer, particularly in advanced and metastatic cases $(3,103)$. The authors suggested that miR-93 may be critical in the carcinogenesis of gastric cancer. Notably, miR-93, as well as miR-1, may predict a poor survival outcome in gastric cancer patients $(3,112,113)$. Furthermore, Tsai et al demonstrated that miR-196a may be a novel biomarker for detecting gastric cancer and monitoring disease recurrence (114). Multivariate analyses have indicated that low miR-125a-3p expression is an independent prognostic factor for survival, while in vitro assays have demonstrated that miR-125a-3p suppresses the proliferation of gastric cancer cells (115).

Therefore, the continuous investigation of gastric cancer-associated miRNAs may lead them to become new assessment biomarkers following treatment for gastric cancer. These biomarkers may not only increase the effectiveness of the evaluation but may also become the main basis of this evaluation.

\section{Serum/plasma miRNAs as biomarkers/signaling molecules for gastric cancer}

At present, the majority of the discoveries of gastric cancer-associated miRNAs have been based on gastric carcinoma and adjacent normal tissues. Since this is an invasive approach, it is a significant request to make of patients and not one that is readily accepted. However, great progress has been made in investigating whether serum and plasma miRNAs may be used as non-invasive biomarkers for the diagnosis, treatment and detection of prognosis in gastric cancer patients. Tsujiura et al published a study demonstrating that plasma miRNA assays have several potential clinical uses, including for screening patients at a high risk of gastric cancer and monitoring disease recurrence during the follow-up period after gastrectomy (5). These miRNA biomarkers may be powerful and useful for confirming the completeness of tumor resection and evaluating the efficacy of adjuvant therapies if the clearance of plasma miRNAs may be elucidated (5). In addition, Konishi et al observed that plasma miR-451 and miR-486 may be useful blood-based biomarkers for the screening of gastric cancer. The authors noted that the levels of these two miRNAs decrease in post-operative plasma in 90 and $93 \%$ of patients, respectively. However, in comparison with healthy controls, the levels of the two miRNAs were demonstrated to be significantly higher in the plasma of post-operative patients (116). The results of further studies have shown that the levels of circulating miR-17-5p/20a may be a promising non-invasive molecular marker for pathological progression, predicting prognosis and monitoring chemotherapeutic effects for gastric cancer (117). Studies have also shown that serum miR-221, miR-376c, miR-744 and miR-378 have clear potential as novel non-invasive biomarkers for the early detection of gastric cancer, and that miR-378 may be used as a valuable biomarker alone $(118,119)$. These findings have pioneered a new approach for the diagnosis and treatment of gastric cancer and demonstrated that miRNAs are likely to become a routine examination indicator for the development and prognosis of gastric cancer, similar to CA199, p53 or other tumor markers.

As mentioned previously, miRNAs are extremely stable in blood plasma and serum (56). Consequently, this makes miRNA levels as suitable for testing for clinical diagnosis as tumor markers and biomarkers. The source of the miRNAs circulating in blood samples remains unclear. Chim et al suggested two hypotheses for this: The presence of circulating miRNAs may be due to tumor cell death and lysis or they may be released by tumor cells into the extracellular microenvironment of blood vessels (120). Ohshima et al demonstrated that the amount of total RNA in culture media was relatively higher in the NCI-H69, Lu-135 and Colo205 cell lines compared with in the exosomes, which was consistent with the 'tumor cell death' hypothesis. However, the authors also revealed that the let-7 miRNA family is selectively secreted into serum and plasma via exosomes in metastatic gastric cancer cell lines (121), while Tanaka et al demonstrated that the level of miR-92a was decreased in the blood plasma of acute leukemia patients while remaining high in the tissue samples (121). These results demonstrated that miRNAs may serve as signaling molecules transferred by exosomes between tumor cells and serum/plasma.

Most significantly, circulating miRNAs are not only tumor biomarkers for gastric cancer, but also signaling molecules involved in the proliferation, tumorigenesis and metastasis of gastric cancer.

\section{Conclusions}

In summary, increasing attention is being paid to miRNAs in gastric cancer. To identify the best approach for the diagnosis, treatment and evaluation of the prognosis of gastric cancer via miRNAs, the detection of serum/plasma miRNAs is likely to be the first choice. However, to make this a reality, breakthroughs are required in the following areas: i) Determining the source of circulating miRNAs; ii) validating a classical pathway of circulating miRNA transmittance; iii) clarifying the mechanism of the action of various circulating miRNAs in gastric cancer; iv) determining how the circulating miRNAs in different stages of gastric cancer development are expressed and how miRNAs develop in this development process; v) highly specific and sensitive detection of miRNA pre- and post-operatively, as well as at various stages of gastric cancer; vi) clarifying the mechanism of synergy/antagonism of various circulating miRNAs in the occurrence and development of gastric cancer; and vii) determining the feasibility of certain miRNA target therapies at different stages of gastric cancer according to associated miRNA specificity.

\section{Acknowledgements}

The present study was partially supported by the National Natural Science Foundation of China (81172348, 81102078), the Jiangsu Province Health Department Research Project (H201313) and the Suzhou Social Development Fund Project (200823). 


\section{References}

1. Jemal A, Bray F, Center MM, Ferlay J, Ward E and Forman D: Global cancer statistics. CA Cancer J Clin 61: 69-90, 2011.

2. Schoof CR, Botelho EL, Izzotti A and Vasques Ldos R: MicroRNAs in cancer treatment and prognosis. Am J Cancer Res 2: 414-433, 2012.

3. Yu BQ, Su LP, Li JF, Cai Q, Yan M, Chen XH, et al: microRNA expression signature of gastric cancer cells relative to normal gastric mucosa. Mol Med Rep 6: 821-826, 2012.

4. Ueda T, Volinia S, Okumura H, Shimizu M, Taccioli C, Rossi S, et al: Relation between microRNA expression and progression and prognosis of gastric cancer: a microRNA expression analysis. Lancet Oncol 11: 136-146, 2010.

5. Tsujiura M, Ichikawa D, Komatsu S, Shiozaki A, Takeshita H, Kosuga T, et al: Circulating microRNAs in plasma of patients with gastric cancers. Br J Cancer 102: 1174-1179, 2010.

6. Lee RC, Feinbaum RL and Ambros V: The $C$. elegans heterochronic gene lin-4 encodes small RNAs with antisense complementarity to lin-14. Cell 75: 843-854, 1993.

7. Wightman B, Ha I and Ruvkun G: Posttranscriptional regulation of the heterochronic gene lin-14 by lin- 4 mediates temporal pattern formation in C. elegans. Cell 75: 855-862, 1993.

8. Reinhart BJ, Slack FJ, Basson M, Pasquinelli AE, Bettinger JC, Rougvie AE, et al: The 21-nucleotide let-7 RNA regulates developmental timing in Caenorhabditis elegans. Nature 403 901-906, 2000

9. Hutvagner G, McLachlan J, Pasquinelli AE, et al: A cellular function for the RNA-interference enzyme Dicer in the maturation of the let-7 small temporal RNA. Science 293: 834-838, 2001.

10. Han J, Lee Y, Yeom KH, Nam JW, Heo I, Rhee JK, et al: Molecular basis for the recognition of primary microRNAs by the Drosha-DGCR8 complex. Cell 125: 887-901, 2006.

11. Klase Z, Houzet L and Jeang KT: Replication competent HIV-1 viruses that express intragenomic microRNA reveal discrete RNA-interference mechanisms that affect viral replication. Cel Biosci 1: 38, 2011.

12. Bernstein E, Caudy AA, Hammond SM and Hannon GJ: Role for a bidentate ribonuclease in the initiation step of RNA interference. Nature 409: 363-366, 2001.

13. Han J, Lee Y, Yeom KH, Kim YK, Jin H and Kim VN: The Drosha-DGCR8 complex in primary microRNA processing. Genes Dev 18: 3016-3027, 2004

14. Lee Y, Kim M, Han J, Yeom KH, Lee S, Baek SH and Kim VN MicroRNA genes are transcribed by RNA polymerase II. EMBO J 23: 4051-4060, 2004

15. Cai X, Hagedorn $\mathrm{CH}$ and Cullen BR: Human microRNAs are processed from capped, polyadenylated transcripts that can also function as mRNAs. RNA 10: 1957-1966, 2004

16. Kim YK and Kim VN: Processing of intronic microRNAs. EMBO J 26: 775-783, 2007.

17. Kim VN: MicroRNA biogenesis: coordinated cropping and dicing. Nat Rev Mol Cell Biol 6: 376-385, 2005.

18. Kusenda B, Mraz M, Mayer J and Pospisilova S: MicroRNA biogenesis, functionality and cancer relevance. Biomed Pap Med Fac Univ Palacky Olomouc Czech Repub 150: 205-215, 2006.

19. Place RF, Li LC, Pookot D, Noonan EJ and Dahiya R: MicroRNA-373 induces expression of genes with complementary promoter sequences. Proc Natl Acad Sci USA 105: 1608-1613, 2008.

20. Vasudevan S, Tong Y and Steitz JA: Switching from repression to activation: microRNAs can up-regulate translation. Science 318 : 1931-1934, 2007.

21. Mattaj IW, Tollervey D and Séraphin B: Small nuclear RNAs in messenger RNA and ribosomal RNA processing. FASEB J 7 : 47-53, 1993.

22. Bachellerie JP, Cavaillé $\mathrm{J}$ and Hüttenhofer A: The expanding snoRNA world. Biochimie 84: 775-790, 2002.

23. Ambros V, Lee RC, Lavanway A, Williams PT and Jewell D MicroRNAs and other tiny endogenous RNAs in C. elegans. Curr Biol 13: 807-818, 2003 .

24. Du T and Zamore PD: microPrimer: the biogenesis and function of microRNA. Development 132: 4645-4652, 2005.

25. Lim LP, Glasner ME, Yekta S, Burge CB and Bartel DP Vertebrate microRNA genes. Science 299: 1540, 2003.

26. Chan JA, Krichevsky AM and Kosik KS: MicroRNA-21 is an antiapoptotic factor in human glioblastoma cells. Cancer Res 65 6029-6033, 2005
27. Cheng AM, Byrom MW, Shelton J and Ford LP: Antisense inhibition of human miRNAs and indications for an involvement of miRNA in cell growth and apoptosis. Nucleic Acids Res 33: 1290-1297, 2005

28. Santarpia L, Nicoloso M and Calin GA: MicroRNAs: a complex regulatory network drives the acquisition of malignant cell phenotype. Endocr Relat Cancer 17: F51-F75, 2010.

29. Mattie MD, Benz CC, Bowers J, et al: Optimized high-throughput microRNA expression profiling provides novel biomarker assessment of clinical prostate and breast cancer biopsies. Mol Cancer 5: 24, 2006.

30. Volinia S, Calin GA, Liu CG, Ambs S, Cimmino A, Petrocca F, et al: A microRNA expression signature of human solid tumors defines cancer gene targets. Proc Natl Acad Sci USA 103: 2257-2261, 2006.

31. Grady WM, Parkin RK, Mitchell PS, Lee JH, Kim YH, Tsuchiya KD, et al: Epigenetic silencing of the intronic microRNA hsa-miR-342 and its host gene EVL in colorectal cancer. Oncogene 27: 3880-3888, 2008

32. Lanza G, Ferracin M, Gafà R, Veronese A, Spizzo R, Pichiorri $\mathrm{F}$, et al: $\mathrm{mRNA} /$ microRNA gene expression profile in microsatellite unstable colorectal cancer. Mol Cancer 6: 54, 2007.

33. Gaur A, Jewell DA, Liang Y, Ridzon D, Moore JH, Chen C, et al: Characterization of microRNA expression levels and their biological correlates in human cancer cell lines. Cancer Res 67: 2456-2468, 2007

34. Saito Y, Suzuki H and Hibi T: The role of microRNAs in gastrointestinal cancers. J Gastroenterol 44 (Suppl 19): 18-22, 2009.

35. Ma L, Young J, Prabhala H, Pan E, Mestdagh P, Muth D et al: miR-9, a MYC/MYCN-activated microRNA, regulates E-cadherin and cancer metastasis. Nat Cell Biol 12: 247-256, 2010.

36. Noonan EJ, Place RF, Basak S, Pookot D and Li LC: miR-449a causes $\mathrm{Rb}$-dependent cell cycle arrest and senescence in prostate cancer cells. Oncotarget 1: 349-358, 2010.

37. Pulikkan JA, Dengler V, Peramangalam PS, Peer Zada AA, Müller-Tidow C, Bohlander SK, et al: Cell-cycle regulator E2F1 and microRNA-223 comprise an autoregulatory negative feedback loop in acute myeloid leukemia. Blood 115: 1768-1778, 2010.

38. Hermeking H: The miR-34 family in cancer and apoptosis. Cell Death Differ 17: 193-199, 2010.

39. Vogt M, Munding J, Grüner M, Liffers ST, Verdoodt B, Hauk J, et al: Frequent concomitant inactivation of miR-34a and $\mathrm{miR}-34 \mathrm{~b} / \mathrm{c}$ by $\mathrm{CpG}$ methylation in colorectal, pancreatic, mammary, ovarian, urothelial, and renal cell carcinomas and soft tissue sarcomas. Virchows Arch 458: 313-322, 2011.

40. Allgayer H: Pdcd4, a colon cancer prognostic that is regulated by a microRNA. Crit Rev Oncol Hematol 73: 185-191, 2010.

41. Lu Z, Liu M, Stribinskis V, Klinge CM, Ramos KS, Colburn NH and Li Y: MicroRNA-21 promotes cell transformation by targeting the programmed cell death 4 gene. Oncogene 27: 4373-4379, 2008

42. Dews M,Homayouni A, Yu D, Murphy D, Sevignani C, WentzelE, et al: Augmentation of tumor angiogenesis by a Myc-activated microRNA cluster. Nat Genet 38: 1060-1065, 2006.

43. Spizzo R, Nicoloso MS, Lupini L, Lu Y, Fogarty J, Rossi S, et al: miR-145 participates with TP53 in a death-promoting regulatory loop and targets estrogen receptor-alpha in human breast cancer cells. Cell Death Differ 17: 246-254, 2010.

44. Hao J, Zhang S, Zhou Y, Hu X and Shao C: MicroRNA 483-3p suppresses the expression of DPC4/Smad4 in pancreatic cancer. FEBS Lett 585: 207-213, 2011.

45. Hao J, Zhang S, Zhou Y, Liu C, Hu X and Shao C: MicroRNA 421 suppresses DPC4/Smad4 in pancreatic cancer. Biochem Biophys Res Commun 406: 552-557, 2011

46. Zhang Y, Takahashi S, Tasaka A, Yoshima T, Ochi H and Chayama K: Involvement of microRNA-224 in cell proliferation, migration, invasion and anti-apoptosis in hepatocellular carcinoma. J Gastroenterol Hepatol 28: 565-575, 2013.

47. Hudson RS, Yi M, Esposito D, Glynn SA, Starks AM, Yang Y, et al: MicroRNA-106b-25 cluster expression is associated with early disease recurrence and targets caspase-7 and focal adhesion in human prostate cancer. Oncogene Sep 17, 2012 (Epub ahead of print).

48. Kasinski AL and Slack FJ: miRNA-34 prevents cancer initiation and progression in a therapeutically resistant K-ras and p53-induced mouse model of lung adenocarcinoma. Cancer Res 72: 5576-5587, 2012 
49. Panarelli NC and Yantiss RK: MicroRNA Expression in Selected Carcinomas of the Gastrointestinal Tract. Patholog Res Int 2011: 124608, 2011.

50. Tokumaru Y, Yamashita K, Osada M, et al: Inverse correlation between cyclin A1 hypermethylation and p53 mutation in head and neck cancer identified by reversal of epigenetic silencing. Cancer Res 64: 5982-5987, 2004.

51. Wittmann J and Jäck HM: Serum microRNAs as powerful cancer biomarkers. Biochim Biophys Acta 1806: 200-207, 2010.

52. Krutovskikh VA and Herceg Z: Oncogenic microRNAs (OncomiRs) as a new class of cancer biomarkers. Bioessays 32 : 894-904, 2010.

53. Brase JC, Wuttig D, Kuner R and Sültmann H: Serum microRNAs as non-invasive biomarkers for cancer. Mol Cancer 9: 306, 2010.

54. Lawrie CH, Gal S, Dunlop HM, Pushkaran B, Liggins AP, Pulford K, et al: Detection of elevated levels of tumour-associated microRNAs in serum of patients with diffuse large B-cell lymphoma. Br J Haematol 141: 672-675, 2008.

55. Wang J, Chen J, Chang P, LeBlanc A, Li D, Abbruzzesse JL, et al: MicroRNAs in plasma of pancreatic ductal adenocarcinoma patients as novel blood-based biomarkers of disease. Cancer Prev Res (Phila) 2: 807-813, 2009.

56. Mitchell PS, Parkin RK, Kroh EM, Fritz BR, Wyman SK, Pogosova-Agadjanyan EL, et al: Circulating microRNAs as stable blood-based markers for cancer detection. Proc Natl Acad Sci USA 105: 10513-10518, 2008.

57. Ng EK, Chong WW, Jin H, Lam EK, Shin VY, Yu J, et al: Differential expression of microRNAs in plasma of patients with colorectal cancer: a potential marker for colorectal cancer screening. Gut 58: 1375-1381, 2009.

58. Cheng H, Zhang L, Cogdell DE, Zheng H, Schetter AJ, Nykter M, et al: Circulating plasma MiR-141 is a novel biomarker for metastatic colon cancer and predicts poor prognosis. PLoS One 6 : e17745, 2011

59. Huang Z, Huang D, Ni S, Peng Z, Sheng W and Du X: Plasma microRNAs are promising novel biomarkers for early detection of colorectal cancer. Int J Cancer 127: 118-126, 2010.

60. Wang LG and Gu J: Serum microRNA-29a is a promising novel marker for early detection of colorectal liver metastasis. Cancer Epidemiol 36: e61-e67, 2012.

61. Luo X, Burwinkel B, Tao S and Brenner H: MicroRNA signatures: novel biomarker for colorectal cancer? Cancer Epidemiol Biomarkers Prev 20: 1272-1286, 2011.

62. Pu XX, Huang GL, Guo HQ, Guo CC, Li H, Ye S, et al: Circulating miR-221 directly amplified from plasma is a potential diagnostic and prognostic marker of colorectal cancer and is correlated with p53 expression. J Gastroenterol Hepatol 25: 1674-1680, 2010.

63. Hennessey PT, Sanford T, Choudhary A, Mydlarz WW, Brown D, Adai AT, et al: Serum microRNA biomarkers for detection of non-small cell lung cancer. PLoS One 7: e32307, 2012.

64. Yuxia M, Zhennan T and Wei Z: Circulating miR-125b is a novel biomarker for screening non-small-cell lung cancer and predicts poor prognosis. J Cancer Res Clin Oncol 138: 2045-2050, 2012.

65. Kosaka N, Iguchi $\mathrm{H}$ and Ochiya T: Circulating microRNA in body fluid: a new potential biomarker for cancer diagnosis and prognosis. Cancer Sci 101: 2087-2092, 2010.

66. Bou Kheir T, Futoma-Kazmierczak E, Jacobsen A, Krogh A, Bardram L, Hother C, et al: miR-449 inhibits cell proliferation and is down-regulated in gastric cancer. Mol Cancer 10: 29, 2011

67. Zhang Z, Li Z, Gao C, Chen P, Chen J, Liu W, et al: miR-21 plays a pivotal role in gastric cancer pathogenesis and progression. Lab Invest 88: 1358-1366, 2008

68. Zhang BG, Li JF, Yu BQ, Zhu ZG, Liu BY and Yan M: microRNA-21 promotes tumor proliferation and invasion in gastric cancer by targeting PTEN. Oncol Rep 27: 1019-1026, 2012.

69. Luo H, Zhang H, Zhang Z, Zhang X, Ning B, Guo J, et al: Down-regulated miR-9 and miR-433 in human gastric carcinoma. J Exp Clin Cancer Res 28: 82, 2009.

70. Kim YK, Yu J, Han TS, Park SY, Namkoong B, Kim DH, et al: Functional links between clustered microRNAs: suppression of cell-cycle inhibitors by microRNA clusters in gastric cancer. Nucleic Acids Res 37: 1672-1681, 2009.

71. Tsukamoto Y, Nakada C, Noguchi T, Tanigawa M, Nguyen LT, Uchida T, et al: MicroRNA-375 is downregulated in gastric carcinomas and regulates cell survival by targeting PDK1 and 14-3-3zeta. Cancer Res 70: 2339-2349, 2010.

72. Ding L, Xu Y, Zhang W, Deng Y, Si M, Du Y, et al: MiR-375 frequently downregulated in gastric cancer inhibits cell proliferation by targeting JAK2. Cell Res 20: 784-793, 2010.
73. Xu Y, Deng Y, Yan X and Zhou T: Targeting miR-375 in gastric cancer. Expert Opin Ther Targets 15: 961-972, 2011.

74. Wan HY, Guo LM, Liu T, Liu M, Li X and Tang H: Regulation of the transcription factor NF-kappaB1 by microRNA-9 in human gastric adenocarcinoma. Mol Cancer 9: 16, 2010.

75. Du Y, Xu Y, Ding L, Yao H, Yu H,Zhou Tand Si J: Down-regulation of miR-141 in gastric cancer and its involvement in cell growth. J Gastroenterol 44: 556-561, 2009.

76. Zhang Y, Fan KJ, Sun Q, Chen AZ, Shen WL, Zhao ZH, et al: Functional screening for miRNAs targeting Smad4 identified miR-199a as a negative regulator of TGF- $\beta$ signalling pathway. Nucleic Acids Res 40: 9286-9297, 2012.

77. Zhang X, Nie Y, Du Y, Cao J, Shen B and Li Y: MicroRNA-181a promotes gastric cancer by negatively regulating tumor suppressor KLF6. Tumour Biol 33: 1589-1597, 2012.

78. Chen L, Yang Q, Kong WQ, Liu T, Liu M, Li X and Tang H: MicroRNA-181b targets cAMP responsive element binding protein 1 in gastric adenocarcinomas. IUBMB Life 64: 628-635, 2012.

79. Xia J, Wu Z, Yu C, He W, Zheng H, He Y, et al: miR-124 inhibits cell proliferation in gastric cancer through down-regulation of SPHK1. J Pathol 227: 470-480, 2012.

80. Li C, Nie H, Wang M, Su L, Li J, Yu B, et al: MicroRNA-409-3p regulates cell proliferation and apoptosis by targeting PHF10 in gastric cancer. Cancer Lett 320: 189-197, 2012.

81. Kong WQ, Bai R, Liu T, Cai CL, Liu M, Li X and Tang H: MicroRNA-182 targets cAMP-responsive element-binding protein 1 and suppresses cell growth in human gastric adenocarcinoma. FEBS J 279: 1252-1260, 2012.

82. Li J, Guo Y, Liang X, Sun M, Wang G, De W and Wu W: MicroRNA-223 functions as an oncogene in human gastric cancer by targeting $\mathrm{FBXW} 7 / \mathrm{hCdc} 4$. J Cancer Res Clin Oncol 138: 763-774, 2012.

83. Zheng B, Liang L, Huang S, Zha R, Liu L, Jia D, et al: MicroRNA-409 suppresses tumour cell invasion and metastasis by directly targeting radixin in gastric cancers. Oncogene 31: 4509-4516, 2012.

84. Zhang Z, Liu S, Shi R and Zhao G: miR-27 promotes human gastric cancer cell metastasis by inducing epithelial-to-mesenchymal transition. Cancer Genet 204: 486-491, 2011.

85. Wang M, Li C, Nie H, Lv X, Qu Y, Yu B, et al: Down-regulated miR-625 suppresses invasion and metastasis of gastric cancer by targeting ILK. FEBS Lett 586: 2382-2388, 2012.

86. Li Z, Cao Y, Jie Z, Liu Y, Li Y, Li J, et al: miR-495 and miR-551a inhibit the migration and invasion of human gastric cancer cells by directly interacting with PRL-3. Cancer Lett 323: 41-47, 2012.

87. Liu Z, Zhu J, Cao H, Ren H and Fang X: miR-10b promotes cell invasion through RhoC-AKT signaling pathway by targeting HOXD10 in gastric cancer. Int J Oncol 40: 1553-1560, 2012.

88. Liao YL, Hu LY, Tsai KW, Wu CW, Chan WC, Li SC, et al: Transcriptional regulation of miR-196b by ETS2 in gastric cancer cells. Carcinogenesis 33: 760-769, 2012.

89. Gao P, Xing AY, Zhou GY, Zhang TG, Zhang JP, Gao C, et al: The molecular mechanism of microRNA-145 to suppress invasion-metastasis cascade in gastric cancer. Oncogene 32: 491-501, 2013.

90. Wang J, Zhang J, Wu J, Luo D, Su K, Shi W, et al: MicroRNA-610 inhibits the migration and invasion of gastric cancer cells by suppressing the expression of vasodilator-stimulated phosphoprotein. Eur J Cancer 48: 1904-1913, 2012.

91. Leja M, Wex T and Malfertheiner P: Markers for gastric cancer premalignant lesions: where do we go? Dig Dis 30: 268-276, 2012.

92. Calin GA and Croce CM: MicroRNA signatures in human cancers. Nat Rev Cancer 6: 857-866, 2006.

93. Chan SH, Wu CW, Li AF, Chi CW and Lin WC: miR-21 microRNA expression in human gastric carcinomas and its clinical association. Anticancer Res 28: 907-911, 2008.

94. Xu Y, Sun J, Xu J, Li Q, Guo Y and Zhang Q: miR-21 Is a Promising Novel Biomarker for Lymph Node Metastasis in Patients with Gastric Cancer. Gastroenterol Res Pract 2012: 640168, 2012.

95. Xiao B, Guo J, Miao Y, Jiang Z, Huan R, Zhang Y, et al: Detection of miR-106a in gastric carcinoma and its clinical significance. Clin Chim Acta 400: 97-102, 2009.

96. Chiang Y, Song Y, Wang Z, Chen Y, Yue Z, Xu H, et al: Aberrant expression of miR-203 and its clinical significance in gastric and colorectal cancers. J Gastrointest Surg 15: 63-70, 2011. 
97. Takagi T, Iio A, Nakagawa Y, Naoe T, Tanigawa N and Akao Y: Decreased expression of microRNA-143 and -145 in human gastric cancers. Oncology 77: 12-21, 2009.

98. Su Y, Ni Z, Wang G, Cui J, Wei C, Wang J, et al: Aberrant expression of microRNAs in gastric cancer and biological significance of miR-574-3p. Int Immunopharmacol 13: 468-475, 2012.

99. Guo JX, Tao QS, Lou PR, Chen XC, Chen J and Yuan GB: miR-181b as a potential molecular target for anticancer therapy of gastric neoplasms. Asian Pac J Cancer Prev 13: 2263-2267, 2012.

100.Zhao X, Dou W, He L, Liang S, Tie J, Liu C, et al: MicroRNA-7 functions as an anti-metastatic microRNA in gastric cancer by targeting insulin-like growth factor-1 receptor. Oncogene 32: 1363-1372, 2013.

101. Jiang W, Chen X, Liao M, et al: Identification of links between small molecules and miRNAs in human cancers based on transcriptional responses. Sci Rep 2: 282, 2012.

102.Liu T, Tang H, Lang Y, Liu M and Li X: MicroRNA-27a functions as an oncogene in gastric adenocarcinoma by targeting prohibitin. Cancer Lett 273: 233-242, 2009.

103. Jiang Z, Guo J, Xiao B, Miao Y, Huang R, Li D and Zhang Y: Increased expression of miR-421 in human gastric carcinoma and its clinical association. J Gastroenterol 45: 17-23, 2010.

104. Link A, Kupcinskas J, Wex T, et al: Macro-role of microRNA in gastric cancer. Dig Dis 30: 255-267, 2012.

105. Tarasov V, Jung P, Verdoodt B, Lodygin D, Epanchintsev A, Menssen A, et al: Differential regulation of microRNAs by p53 revealed by massively parallel sequencing: $\mathrm{miR}-34 \mathrm{a}$ is a p53 target that induces apoptosis and G1-arrest. Cell Cycle 6: 1586-1593, 2007.

106.Ji Q, Hao X, Meng Y, Zhang M, Desano J, Fan D and Xu L: Restoration of tumor suppressor miR-34 inhibits human p53-mutant gastric cancer tumorspheres. BMC Cancer 8: 266, 2008.

107.Xia L, Zhang D, Du R, Pan Y, Zhao L, Sun S, et al: miR-15b and miR-16 modulate multidrug resistance by targeting BCL2 in human gastric cancer cells. Int J Cancer 123: 372-379, 2008.

108. Shen J, Wan R, Hu G, et al: miR-15b and miR-16 induce the apoptosis of rat activated pancreatic stellate cells by targeting Bcl-2 in vitro. Pancreatology 12: 91-99, 2012.

109. Wang J, Wang Q, Liu H, Hu B, Zhou W and Cheng Y: MicroRNA expression and its implication for the diagnosis and therapeutic strategies of gastric cancer. Cancer Lett 297: 137-143, 2010.
110. LastraioliE, Romoli MR and Arcangeli A: Immunohistochemical biomarkers in gastric cancer research and management. Int J Surg Oncol 2012: 868645, 2012.

111. Grady WM and Tewari M: The next thing in prognostic molecular markers: microRNA signatures of cancer. Gut 59 706-708, 2010.

112. Chen L, Jiang M, Yuan W and Tang H: Prognostic value of miR-93 overexpression in resectable gastric adenocarcinomas. Acta Gastroenterol Belg 75: 22-27, 2012.

113. Inoue $T$, Iinuma $H$, Ogawa $E$, Inaba $T$ and Fukushima $R$ : Clinicopathological and prognostic significance of microRNA-107 and its relationship to DICER1 mRNA expression in gastric cancer. Oncol Rep 27: 1759-1764, 2012.

114. Tsai KW, Liao YL, Wu CW, Hu LY, Li SC, Chan WC, et al: Aberrant expression of miR-196a in gastric cancers and correlation with recurrence. Genes Chromosomes Cancer 51: 394-401, 2012

115. Hashiguchi Y, Nishida N, Mimori K, Sudo T, Tanaka F, Shibata K, et al: Down-regulation of miR-125a-3p in human gastric cancer and its clinicopathological significance. Int J Oncol 40: 1477-1482, 2012.

116. Konishi H, Ichikawa D, Komatsu S, Shiozaki A, Tsujiura M, Takeshita $\mathrm{H}$, et al: Detection of gastric cancer-associated microRNAs on microRNA microarray comparing pre- and post-operative plasma. Br J Cancer 106: 740-747, 2012

117. Wang M, Gu H, Wang S, Qian H, Zhu W, Zhang L, et al: Circulating miR-17-5p and miR-20a: molecular markers for gastric cancer. Mol Med Report 5: 1514-1520, 2012.

118. Song MY, Pan KF, Su HJ, Zhang L, Ma JL, Li JY, et al: Identification of serum microRNAs as novel non-invasive biomarkers for early detection of gastric cancer. PLoS One 7: e33608, 2012.

119. Liu H, Zhu L, Liu B, Yang L, Meng X, Zhang W, et al: Genome-wide microRNA profiles identify miR-378 as a serum biomarker for early detection of gastric cancer. Cancer Lett 316: 196-203, 2012.

120. Chim SS, Shing TK, Hung EC, Leung TY, Lau TK, Chiu RW and Lo YM: Detection and characterization of placental microRNAs in maternal plasma. Clin Chem 54: 482-490, 2008.

121. Ohshima K, Inoue K, Fujiwara A, Hatakeyama K, Kanto K, Watanabe Y, et al: Let-7 microRNA family is selectively secreted into the extracellular environment via exosomes in a metastatic gastric cancer cell line. PLoS One 5: e13247, 2010. 